\title{
The incorporation of an organic soil layer in the Noah-MP land surface model and its evaluation over a boreal aspen forest
}

\author{
Liang Chen ${ }^{1,2}$, Yanping Li ${ }^{1}$, Fei Chen ${ }^{3}$, Alan Barr ${ }^{4}$, Michael Barlage ${ }^{3}$, and Bingcheng Wan ${ }^{3}$ \\ ${ }^{1}$ Global Institute for Water Security, University of Saskatchewan, Saskatoon, SK, Canada \\ ${ }^{2}$ Key Laboratory of Regional Climate Environment for Temperate East Asia, Institute of Atmospheric Physics, \\ Chinese Academy of Sciences, Beijing, China \\ ${ }^{3}$ National Center for Atmospheric Research, Boulder, Colorado, USA \\ ${ }^{4}$ Environment Canada, National Hydrology Research Center, Saskatoon, SK, Canada
}

Correspondence to: Yanping Li (yanping.li@usask.ca)

Received: 12 July 2015 - Published in Atmos. Chem. Phys. Discuss.: 28 October 2015

Revised: 6 June 2016 - Accepted: 10 June 2016 - Published: 12 July 2016

\begin{abstract}
A thick top layer of organic matter is a dominant feature in boreal forests and can impact land-atmosphere interactions. In this study, the multi-parameterization version of the Noah land surface model (Noah-MP) was used to investigate the impact of incorporating a forest-floor organic soil layer on the simulated surface energy and water cycle components at the BERMS Old Aspen site (OAS) field station in central Saskatchewan, Canada. Compared to a simulation without an organic soil parameterization (CTL), the Noah-MP simulation with an organic soil (OGN) improved Noah-MP-simulated soil temperature profiles and soil moisture at $40-100 \mathrm{~cm}$, especially the phase and amplitude (Seasonal cycle) of soil temperature below $10 \mathrm{~cm}$. OGN also enhanced the simulation of sensible and latent heat fluxes in spring, especially in wet years, which is mostly related to the timing of spring soil thaw and warming. Simulated top-layer soil moisture is better in OGN than that in CTL. The effects of including an organic soil layer on soil temperature are not uniform throughout the soil depth and are more prominent in summer. For drought years, the OGN simulation substantially modified the partitioning of water between direct soil evaporation and vegetation transpiration. For wet years, the OGN-simulated latent heat fluxes are similar to CTL except for the spring season when OGN produced less evaporation, which was closer to observations. Including organic soil produced more subsurface runoff and resulted in much higher runoff throughout the freezing periods in wet years.
\end{abstract}

\section{Introduction}

Land surface processes play an important role in the climate system by controlling land-atmosphere exchanges of momentum, energy, and mass (water, carbon dioxide, and aerosols). Therefore, it is critical to correctly represent these processes in land surface models (LSMs) that are used in weather prediction and climate models (e.g., Dickinson et al., 1986; Sellers et al., 1996; Chen and Dudhia, 2001; Dai et al., 2003; Oleson et al., 2008; Niu et al., 2011). Niu et al. (2011) and Yang et al. (2011) developed the Noah LSM with multi-parameterization options (Noah-MP) and evaluated its simulated seasonal and annual cycles of snow, hydrology, and vegetation in different regions. Noah-MP has been implemented in the community Weather Research and Forecasting (WRF) model (Barlage et al., 2015), which is widely used as a numerical weather prediction and regional climate model for dynamical downscaling in many regions worldwide (Chotamonsak et al., 2012). The performance of Noah-MP was previously evaluated using in situ and satellite data (Niu et al., 2011; Yang et al., 2011; Cai et al., 2014; Pilotto et al., 2015; Chen et al., 2014). Those evaluation results showed significant improvements in modeling runoff, snow, surface heat fluxes, soil moisture, and surface skin temperature compared to the Noah LSM (Chen et al., 1996; Ek et al., 2003). Recently, Chen et al. (2014) compared Noah-MP to Noah and four other LSMs regarding the simulation of snow and surface heat fluxes at a forested site in the Colorado headwaters region, and found a generally good performance 
of Noah-MP. However, it is challenging to parameterize the cascading effects of snow albedo and below-canopy turbulence and radiation transfer in forested regions as pointed out by Clark et al. (2015) and Zheng et al. (2015).

The Canadian boreal region contains one-third of the world's boreal forest, approximately 6 million $\mathrm{km}^{2}$ (Bryant et al., 1997). The boreal forests have complex interactions with the atmosphere and have significant impacts on regional and global climate (Bonan, 1991; Bonan et al., 1992; Thomas and Rowntree, 1992; Viterbo and Betts, 1999; Ciais et al., 1995). Several field experiments were conducted to better understand and model these interactions, including BOREAS (Boreal Ecosystem Atmosphere Study) and BERMS (Boreal Ecosystem Research and Monitoring Sites). Numerous studies have evaluated LSMs using the BOREAS and BERMS data (Bonan, 1997). Levine and Knox (1997) developed a frozen soil temperature (FroST) model to simulate soil moisture and heat flux and used BOREAS northern and southern study areas to calibrate the model. They found that soil temperature was underestimated and large model biases existed when snow was present. Bonan (1997) examined NCAR LSM1 with flux-tower measurements from the BOREAS, and found that the model reasonably simulated the diurnal cycle of the fluxes. Bartlett et al. (2002) used the BOREAS Old Jack Pine (OJP) site to assess two different versions of CLASS, the Canadian Land Scheme (2.7 and 3.0), and found that both versions underestimated the snow depth and soil temperature values, especially the version CLASS 2.7.

Boreal forest soils often have a relatively thick upper organic horizon. The thickness of the organic horizon directly affects the soil thermal regime and soil hydrological processes. Compared with mineral soil, the thermal and hydraulic properties of the organic soil are significantly different. Dingman (1994) found that the mineral soil porosity ranges from 0.4 to 0.6 , while the porosity of organic soil is seldom less than 0.8 (Radforth and Brawner, 1977). The hydraulic conductivity of organic soil horizons can be very high due to the high porosity (Boelter, 1968). Less suction is observed for a given volumetric water content in organic soils than in mineral soils, except when it reaches saturation. The thermal properties of the soil are also affected by the underground hydrology. Organic soil horizons also have relatively low thermal conductivity, relatively high heat capacity, and a relatively high fraction of plant-available water. Prior studies illustrated the importance of parameterizing organic soil horizons in LSMs for simulating soil temperature and moisture (e.g., Letts et al., 2000; Beringer et al., 2001; Mölders and Romanovsky, 2006; Nicolsky et al., 2007; Lawrence and Slater, 2008).

The current Noah-MP model does not include a parameterization for organic soil horizons. It is thus critical to evaluate the effects of incorporating organic matter in surface energy and water budgets in order to enhance the global applicability of the WRF Noah-MP coupled modeling system. Here we conduct a detailed examination of the perfor- mance of the Noah-MP model in a Canadian boreal forest site. The main objective of this research is to enhance the modeling of vertical heterogeneity (such as organic matter) in soil structures and to understand its impacts on the simulated seasonal and annual cycle of soil moisture and surface heat fluxes. We recognize that Noah-MP has weaknesses in existing subprocess parameterizations; however the goal of this study is to explore the impact of incorporating organic soil in surface energy and water budgets, rather than comprehensively addressing errors in existing Noah-MP parameterization schemes. In this paper, we present the BERMS observation site in central Saskatchewan (Sect. 2) and our methodology for conducting 12-year Noah-MP simulations with and without the organic soil layer for that boreal forest site (Sect. 3). Section 4 discusses the simulations of the diurnal and annual cycles of the surface energy and hydrological components, in dry and wet periods. Summary and conclusions are given in Sect. 5.

\section{BERMS site descriptions}

The Old Aspen site (OAS, $53.7^{\circ} \mathrm{N}, 106.2^{\circ} \mathrm{W}$, altitude $\left.601 \mathrm{~m}\right)$ is located in mature deciduous broadleaf forest at the southern edge of the Canadian boreal forest in Prince Albert National Park, Saskatchewan, Canada (Fig. 1). The forest canopy consists of a $22 \mathrm{~m}$ trembling aspen overstory (Populus tremuloides) with $\sim 10 \%$ balsam poplar (Populus balsamifera.) and a $2 \mathrm{~m}$ hazelnut understory (Corylus cornuta) with sparse alder (Alnus crispa). The fully leafed values of the leaf area index varied among years from 2.0 to 2.9 for the aspen overstory and 1.5 to 2.8 for the hazelnut understory (Barr et al., 2004). The forest was regenerated after a natural fire in 1919, and in 1998 it had a stand density of $\sim 830$ stems ha $^{-1}$. The soil is an Orthic Gray Luvisol (Canadian Soil Classification System) with an 8-10 cm deep forest floor (LFH; litter, fibric, and humic) organic horizon overlying a loam Ae horizon $(0-21 \mathrm{~cm})$, a sandy clay loam Bt horizon $(21-69 \mathrm{~cm}$ ), and a sandy clay loam Ck horizon (deeper than $69 \mathrm{~cm}$ ). $30 \%$ of the fine roots are in the LFH horizon and $60 \%$ are in the upper $20 \mathrm{~cm}$ of mineral soil. The water table lies from 1 to $5 \mathrm{~m}$ below the ground surface, varying spatially in the hummocky terrain and varying in time in response to variations in precipitation. A small depression near the tower had ponded water at the surface during the wet period from 2005 to 2010. Mean annual air temperature and precipitation at the nearest long-term weather station are $0.4^{\circ} \mathrm{C}$ and $467 \mathrm{~mm}$, respectively (Waskesiu Lake, $53^{\circ} 55^{\prime} \mathrm{N}, 106^{\circ} 04^{\prime} \mathrm{W}$, altitude 532 m, 1971-2000 climatic normal).

Air temperature and humidity were measured at $36 \mathrm{~m}$ above ground level using a Vaisala model HMP35cf or HMP45cf temperature/humidity sensor (Vaisala Oyj, Helsinki, Finland) in a 12-plate Gill radiation shield (R.M. Young model 41002-2, Traverse City, MI, USA). Wind speed was measured using a propeller anemometer (R.M. 


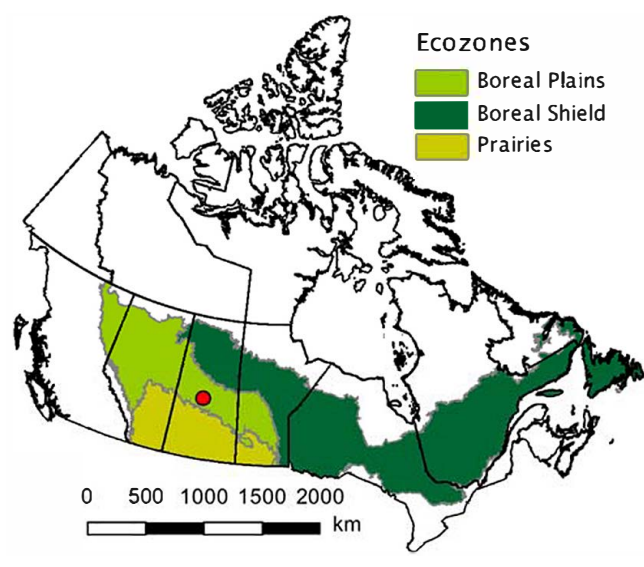

Figure 1. The location of the study site (Old Aspen flux tower).

Young model 01503-, Traverse City, MI, USA) located at $38 \mathrm{~m}$ above ground level. Atmospheric pressure was measured using a barometer (Setra model SBP270, distributed by Campbell Scientific Inc., Logan, UT, USA). Soil temperature was measured using thermocouples in two profiles at depths of $2,5,10,20,50$, and $100 \mathrm{~cm}$. The two upper measurements were in the forest-floor LFH. Soil volumetric water content was measured using TDR probes (Moisture Point Type B, Gabel Corp., Victoria, Canada) with measurements at depths of $0-15,15-30,30-60,60-90$, and $90-120 \mathrm{~cm}$. Three of the eight probes that were the most free of data gaps were used in this analysis. The TDR probes were located in a low-lying area of the site that was partially flooded after 2004, resulting in high volumetric water content (VWC) values that may not be characteristic of the flux footprint. VWC is also measured at 2.5 and $7.5 \mathrm{~cm}$ depth in the forest-floor LFH layer, using two profiles of soil moisture reflect meters (model CS615, Campbell Scientific Inc., Logan, UT, USA), inserted horizontally at a location that did not flood.

Eddy-covariance measurements of the sensible and latent heat flux densities were made at $39 \mathrm{~m}$ above the ground from a twin scaffold tower. Details of the eddy-covariance systems are given in Barr et al. (2006). Data gaps were filled using a standard procedure (Amiro et al., 2006).

The net radiation flux density, $\mathrm{Rn}$, was calculated from component measurements of incoming and outgoing shortwave and long-wave radiation, made using paired Kipp and Zonen (Delft, the Netherlands) model CM11 pyranometers and paired Eppley Laboratory (Newport, RI, USA) model PIR pyrgeometers. The upward-facing radiometers were mounted atop the scaffold flux tower in ventilated housings to minimize dew and frost on the sensor domes. The net radiometer and the downward-facing radiometers were mounted on a horizontal boom that extended $4 \mathrm{~m}$ to the south of the flux tower, $\sim 10 \mathrm{~m}$ above the forest canopy. Details of the minor terms in the surface energy balance, including soil heat flux and biomass heat storage flux, are given in Barr et al. (2006). During the warm season when all com- ponents of the surface energy balance were resolved, the sum of the eddy-covariance sensible and latent heat fluxes underestimated the surface available energy (net radiation minus surface storage) by $\sim 15 \%$ (Barr et al., 2006).

\section{Methodology}

\subsection{The Noah-MP land surface model}

Noah-MP is a new-generation of LSM, which was developed to improve the performance of the Noah LSM (Chen et al., 1996; Chen and Dudhia, 2001). It is coupled to the WRF community weather and regional climate model (Barlage et al., 2015), and also available as a stand-alone 1-D model (Noah-MP v1.1). Noah-MP simulates several biophysical and hydrological processes that control fluxes between the surface and the atmosphere. These processes include surface energy exchange, radiation interactions with the vegetation canopy and the soil, hydrological processes within the canopy and the soil, a multilayer snowpack with freeze-thaw, groundwater dynamics, stomatal conductance, and photosynthesis and ecosystem respiration. The major components include a one-layer canopy, three-layer snow, and four-layer soil. Noah-MP provides a multi-parameterization framework that allows using the model with different combinations of alternative process schemes for individual processes (Niu et al., 2011). Alternative submodules for 12 physical processes can provide more than 5000 different combinations. Soil water fluxes are calculated by the Richards equation using a Campbell/Clapp-Hornberger parameterization of the hydraulic functions (Clapp and Hornberger, 1978).

We use an offline stand-alone 1-D mode (Noah-MP) with four soil layers: $0-10,10-40,40-100$, and $100-200 \mathrm{~cm}$. The selected Noah-MP physics options used in this study are similar to Barlage et al. (2015), Gao et al. (2015) and Chen et al. (2014) and are list in Table 1. In the default configuration of Noah-MP, the entire vertical soil profile was treated as one mineral ground texture only, and no organic soil matter is included.

The OAS research site has an organic LFH (forest floor) soil horizon, $8-10 \mathrm{~cm}$ deep. This study evaluates the impact of adding an organic soil horizon in the Noah-MP model using a similar approach to Lawrence and Slater (2008), which parameterizes soil thermal and hydrologic properties in terms of carbon density in each soil layer. Soil carbon or organic fraction for each layer is determined as

$f_{\mathrm{sc}, i}=\frac{\rho_{\mathrm{sc}, i}}{\rho_{\mathrm{sc}, \max }}$,

where $f_{\mathrm{sc}, i} f_{\mathrm{sc}, i}$ is the carbon fraction of the each layer, $\rho_{\mathrm{sc}, i}$ is the soil carbon density, and $\rho_{\mathrm{sc}, \max }$ is the maximum possible value (peat density of $130 \mathrm{~kg} \mathrm{~m}^{-3}$, Farouki, 1981). In this study, we assume that the topsoil layer is made up of $100 \%$ organic matter, consistent with the $8-10 \mathrm{~cm} \mathrm{LFH} \mathrm{horizon} \mathrm{at}$ 
Table 1. Noah-MP parameterization options used in this study.

\begin{tabular}{ll}
\hline Parameterization description & Options \\
\hline Dynamic vegetation & 4: table LAI, shdfac = maximum \\
Stomatal resistance & 1: BALL-Berry (Ball et al., 1987) \\
Soil moisture factor for stomatal resistance & 1: original Noah (Chen and Dudhia, 2001) \\
Runoff/soil lower boundary & 2: TOPMODEL with equilibrium water table (Niu et al., 2005) \\
Surface layer drag coefficient calculation & 1: Monin-Obukhov (Brutsaert, 1982) \\
Supercooled liquid water & 1: no iteration (Niu and Yang, 2006) \\
Soil permeability & 1: linear effects, more permeable (Niu and Yang, 2006) \\
Radiative transfer & 3: two-stream applied to vegetated fraction \\
Ground surface albedo & 2: CLASS (Verseghy, 1991) \\
Precipitation partitioning between snow and rain & 1: Jordan (Jordan, 1991) \\
Soil temp lower boundary & 2: TBOT at ZBOT (8 m) read from a file \\
Snow/soil temperature time & 1: semi-implicit \\
\hline
\end{tabular}

Table 2. Soil parameters used in Noah-MP for mineral soil texture classes (sandy clay loam) and organic soil (Hemic Peat).

\begin{tabular}{|c|c|c|c|c|c|c|c|c|}
\hline Soil type & $\begin{array}{r}\lambda_{\mathrm{s}} \\
\left(\mathrm{w} \mathrm{m}^{-1} \mathrm{~K}^{-1}\right)\end{array}$ & $\begin{array}{r}\lambda_{\text {sat }} \\
\left(\mathrm{w} \mathrm{m}^{-1} \mathrm{~K}^{-1}\right)\end{array}$ & $\begin{array}{r}\lambda_{\text {dry }} \\
\left(\mathrm{w} \mathrm{m}^{-1} \mathrm{~K}^{-1}\right)\end{array}$ & $\begin{array}{r}c_{\mathrm{S}} \\
\left(\mathrm{J} \mathrm{m}^{-3} \mathrm{~K}^{-1} \times 10^{6}\right)\end{array}$ & $\theta_{\text {sat }}$ & $\left(\mathrm{ms}^{-1} \times 10^{-3}\right)$ & $\begin{array}{r}\psi_{\text {sat }} \\
(\mathrm{mm})\end{array}$ & $b$ \\
\hline Mineral & 6.04 & 2.24 & 0.23 & 2.0 & 0.421 & 0.00445 & -135 & 6.77 \\
\hline Organic & 0.25 & 0.55 & 0.05 & 2.5 & 0.88 & 0.002 & -10.3 & 6.1 \\
\hline
\end{tabular}

The soil parameters are as follows: $\lambda_{\mathrm{s}}$ is the thermal conductivity of soil solids, $\lambda_{\text {sat }}$ is the unfrozen saturated thermal conductivity, $\lambda_{\text {dry }}$ is the dry soil thermal conductivity, $c_{\mathrm{S}}$ is the soil solid heat capacity, $\theta_{\mathrm{sat}}$ is the saturated volumetric water content (porosity), $\kappa_{\mathrm{s} a t}$ is the saturate hydraulic conductivity, $\psi_{\mathrm{sat}}$ is the saturated matric potential, and $b$ is the Clapp and Hornberger parameter.

OAS, with the carbon fraction equal to 1 . The soil properties for this layer are calculated based on the parameters of organic soil. The second layer of the soil is considered to be a transition layer and made up of $30 \%$ organic matter with the carbon fraction equal to 0.3 . The soil properties of this layer are specified as a weighted combination of organic and mineral soil properties:

$P=\left(1-f_{\mathrm{sc}, i}\right) P_{\mathrm{m}}+f_{\mathrm{sc}, i} P_{\mathrm{o}}$,

where $P_{\mathrm{m}}$ is the value for mineral soil, $P_{\mathrm{o}}$ is the value for organic soil, and $P$ is the weighted average. The remaining soil layers were assumed to be $100 \%$ mineral so we conducted sensitivitraction equal to 0 . The soil properties for this layer are calculated based on the parameters of mineral soil. To investigate impacts of uncertainties of those parameters on simulations, we conducted sensitivity tests for key parameters such as saturated hydraulic conductivity, porosity, suction, and the Clapp and Hornberger parameter. Those parameters were perturbed within a 5-20\% range (except for hydraulic conductivity that is changed over 4 times below and above the default value) following the work of Letts et al. (2000). Results showed that the simulated top layer soil moisture is very sensitive to porosity, saturate hydraulic conductivity, saturated matric potential and the Clapp and Hornberger parameter, while other layers are not too sensitive to those parameters. For porosity, as the value increased, the topsoil moisture increased significantly. The saturated hydraulic conductivity mainly influences the unfrozen period.
As the value increased, the topsoil moisture decreased. Saturated matric potential and the Clapp and Hornberger parameter only influence the frozen period. For saturated matric potential, the topsoil moisture decreased when the parameter value increased, while for the Clapp and Hornberger parameter, the topsoil moisture increased when the parameter value increased. Based on the site measurement, the soil bulk density of the top layer is about $160 \mathrm{~kg} \mathrm{~m}^{-3}$. As described in Letts et al. (2000), this organic soil can be defined as hemic peat, a medium humified organic soil. Table 2 gives the recommended parameters for hemic peat, with 0.88, 2.0, 0.0102, and 6.1 for porosity, saturated hydraulic conductivity, saturated matric potential, and the Clapp and Hornberger parameter, respectively (Letts et al., 2000). From the sensitivity test mentioned above, it seems that the recommended values from Letts et al. (2000) produced soil moisture and soil temperature close to observations.

\subsection{Forcing data}

The $30 \mathrm{~min}$ meteorological observations, including air temperature, specific humidity, wind speed, pressure, precipitation, downward solar, and long-wave radiation, at $36 \mathrm{~m}$ height from OAS were used as atmospheric forcing data to drive Noah-MP in an offline 1-D mode. Figure 2 shows the annual mean temperature $\left(1.5^{\circ} \mathrm{C}\right)$ and total precipitation (406 mm) at this site during the study period (1998-2009). The most significant climatic features during the study pe- 


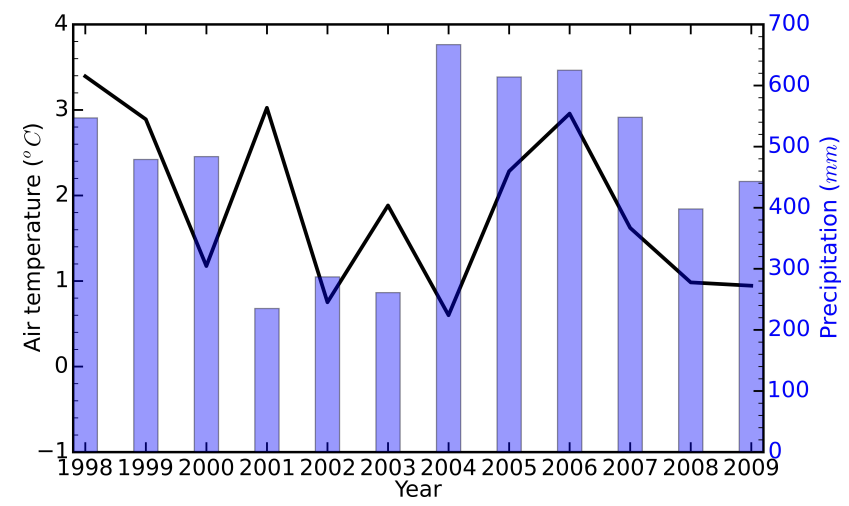

Figure 2. Monthly air temperature above the canopy and precipitation at BERMS SK-OAS site.

riod are a prolonged drought that began in July 2001 and extended throughout 2003, and an extended wet period from 2004 to 2007.

\subsection{Evaluation of model performance}

Outputs from the Noah-MP simulations were evaluated against observations, using the root mean squared error (RMSE), square of the correlation coefficient $\left(R^{2}\right)$, and index of agreement (IOA) (Zhang et al., 2014). The IOA is calculated as

$\mathrm{IOA}=1-\frac{\sum_{i=1}^{N}\left(M_{i}-O_{i}\right)^{2}}{\sum_{i=1}^{N}\left(\left|O_{i}-\bar{O}\right|+\left|M_{i}-\bar{O}\right|\right)^{2}}$,

where $M_{i}$ and $O_{i}$ are simulated and observed values of the same variable, respectively, and $\bar{O}$ is the mean of the observed values. IOA ranges from 0 (no agreement) to 1 (perfect match).

\section{Results and discussions}

\subsection{Noah-MP model spin-up}

The LSM spin-up is broadly defined as an adjustment process as the model approaches its equilibrium following the initial anomalies in soil moisture content or after some abnormal environmental forcing (Yang et al., 1995). Without spinup, the model results may exhibit drift as model states try to approach their equilibrium values. To initialize LSMs properly, the spin-up time required for LSMs to reach the equilibrium stage needs to be examined first (Chen and Mitchell, 1999; Cosgrove et al., 2003). In this study, model runs for the year 1998 were performed repeatedly until all the soil-state variables reached the equilibrium state, defined as when the difference between two consecutive 1-year simulations becomes less than $0.1 \%$ for the annual means (Cai et al., 2014;

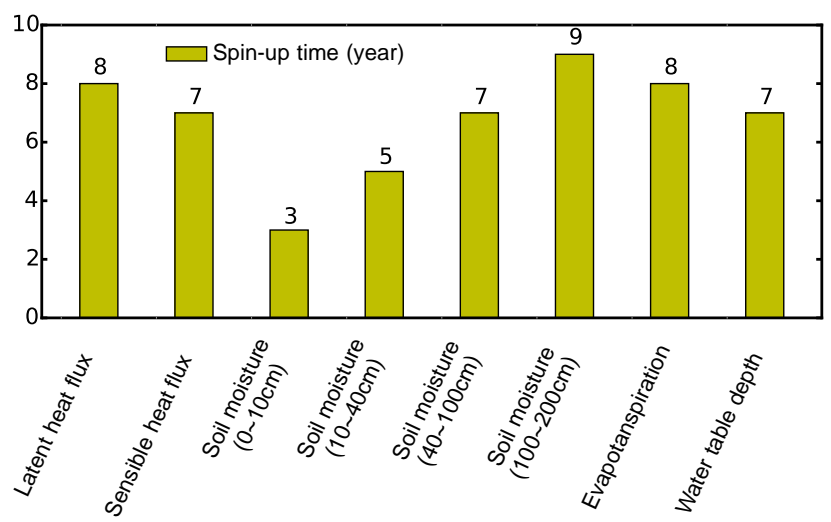

Figure 3. Averaged spin-up time (in years) for individual variables.

Yang et al., 1995). Yang et al. (1995) discussed the spin-up processes by comparing results from 22 LSMs for grass and forest sites, and showed a wide range of spin-up timescales (from 1 to 20 years), depending on the model, state variable, and vegetation type. Cosgrove et al. (2003) used four NLDAS-1 LSMs to discuss the spin-up time at six subregions covering North America, and showed that all models reached equilibrium between 1 and 3 years for all six subregions. In this study, we found that it requires 9 years for deep-soil moisture (100-200 cm layer) in Noah-MP to reach its equilibrium, 8 years for latent heat flux and evapotranspiration, but only 3 years for the surface soil moisture (Fig. 3). Cosgrove et al. (2003) and Chen et al. (1999) indicated that it takes a long time to reach equilibrium, especially in the deep soil layers and sparse vegetation, because the evaporation was limited by slow water diffusion timescales between the surface and deep soil layers. When using the groundwater component of Noah-MP, it might take at least 250 years to spin up the water table depth in arid regions (Niu et al., 2007). Cai et al. (2014) found that water table depth requires less than 10 years to spin up in a wet region, but more than 72 years for a dry region. For this boreal forest site where the water table depth is shallower (less than $2.5 \mathrm{~m}$ ), it takes $\sim 7$ years for water table depth to reach equilibrium. However, the freezing/thawing is a relatively slow process, so we set 10 years for the spin-up time for all the experiments discussed here.

\subsection{Seasonal cycle of soil temperature and moisture}

We defined the simulation without incorporation of organic soil as the control experiment (CTL), and the simulation with the organic soil incorporated as the organic layer experiment (OGN). We first evaluated the CTL- and OGN-simulated soil temperature and moisture at the OAS site in relation to observations for the period of 1998-2009.

As shown in Fig. 4, the effects of including a $10 \mathrm{~cm}$ organic topsoil layer on simulated soil temperature are not uniform both throughout the soil depth and during the year. Figure $4 \mathrm{a}$ 


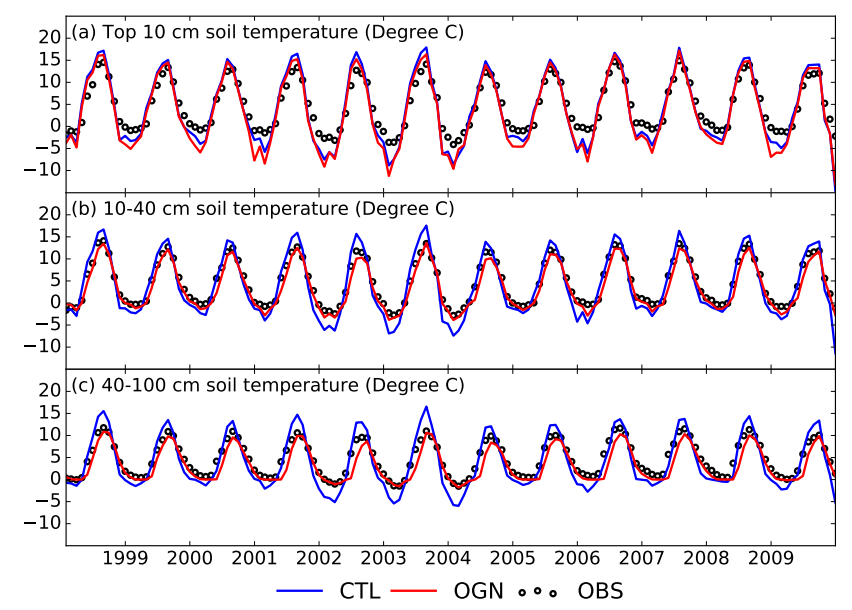

Figure 4. Observed and Noah-MP-simulated monthly soil temperature for BERMS SK-OAS site at a depth of (a) top $10 \mathrm{~cm}$, (b) 10 $40 \mathrm{~cm}$, and (c) $40-100 \mathrm{~cm}$.

shows that the CTL and OGN simulations produced nearly identical top-layer temperatures which are in agreement with the observations except for a low bias in the winter period, especially during drought years 2002-2003. However, for deep layers $(10-100 \mathrm{~cm})$, soil temperature from the OGN is lower (higher) than the CTL simulation during summer (winter), especially for the drought years 2002-2003, leading to a good agreement between OGN and observations for secondand third-layer soil temperature (Fig. 4b, c). Lawrence and Slater (2008) indicated that strong cooling in summer is due to the modulation of early and midsummer soil heat flux, while higher soil temperature in fall and winter is due to less efficient cooling of organic soils. The soil thawing period in spring is significantly affected by the OGN parameterization since the thermal conductivity of the organic horizon is much lower than that of the mineral soil $\left(\sim 0.4 \mathrm{~W} \mathrm{~m}^{-1} \mathrm{~K}^{-1}\right.$ compared to $\sim 2.0 \mathrm{~W} \mathrm{~m}^{-1} \mathrm{~K}^{-1}$ ), which delays the warming of the deep soil layers after snowmelt. In winter, the organic soil layer insulates the soil and results in relatively higher wintertime soil temperatures for OGN compared with CTL. The difference is most pronounced in drought years (2002 and 2003) (Fig. 4). In summer, due to lower saturated thermal conductivity $\left(0.25 \mathrm{~W} \mathrm{~m}^{-1} \mathrm{~K}^{-1}\right.$ for organic compared to $\sim 6.04 \mathrm{~W} \mathrm{~m}^{-1} \mathrm{~K}^{-1}$ for mineral) in OGN, the downward transfer of heat from the topsoil layer is less and the deep soil temperature in OGN is lower than that in CTL.

In winter, with the presence of soil ice, the thermal heat conductivity in OGN $\left(\sim 2.20 \mathrm{~W} \mathrm{~m}^{-1} \mathrm{~K}^{-1}\right)$ is lower than that in CTL ( $\left.6.04 \mathrm{~W} \mathrm{~m}^{-1} \mathrm{~K}^{-1}\right)$; it reduces the upward transfer of heat from deep soils to topsoil and therefore results in higher deep-soil temperature in OGN. These results are consistent with studies that showed a simulated increase in winter soil temperature of up to $5^{\circ} \mathrm{C}$ in boreal regions when including an organic layer (Koven et al., 2009; Rinke et al., 2008; Lawrence and Slater, 2008) in LSMs.
For the topsoil layer, the OGN parameterization increases the liquid soil water content in summer as water fills the larger pore space of organic soil, though the liquid soil water content in winter did not change much, due to the contrasting water retention characteristics of organic and mineral soil (Koven et al., 2009; Rinke et al., 2008; Lawrence and Slater, 2008). Higher porosity in OGN leads to an increase in total soil water content, while the lower topsoil temperature (Fig. 4a) in OGN enhances the ice content. Note that the observed soil water content during wet years may be higher than the site truth because the sensors were located in a low spot that is prone to flooding. This site got flooded in 2004 and the ground water has not dried since then; so the soil was oversaturated during the period of 2004-2008. In the second soil layer, the observed soil water content was incorrect after the site got flooded (2004-2008). With more precipitation during the wet period, the real soil water content should have a relatively high value. Since the OGN increases the soil water content, it should be closer to the true observation. From Fig. 5, it can be seen that the OGN improved the liquid water simulation in non-frozen periods. The soil moisture data are not reliable when the soil is frozen and are therefore not very useful during the winter. In late spring when snow starts melting, both CTL and OGN simulate the same topsoil temperature (Fig. 4). It is clear that the soil liquid water content is mainly controlled by precipitation, soil hydraulic conductivity, and runoff. The high porosity of organic soil in the topsoil layer helps to retain more snowmelt water and hence increases the topsoil layer liquid water content. For the deep soil layers, the soil liquid water content is highly influenced by the soil temperature. Liquid soil water content increases during soil-ice thawing period. The higher deep soil layer liquid water content in OGN is mainly because the soil hydraulic conductivity is higher for organic soil than mineral soil, so liquid water in the first layer can be transported downward quickly into the deeper layers. Although the organic soil layer is only added to the first two layers in this study, it still can affect the deep layer due to the infiltration characteristics of the topsoil.

The water retention characteristics of the organic soil horizon favor both higher water retention and reduced evaporation. The thermal conductivity is lower compared with that of the mineral soil, which then prevents the deeper soil from warming up rapidly after the snowmelt season. The lower thermal conductivity of the top organic soil affects the annual cycle of the ground heat flux. In summer, the top layer is warmer than the deep layers; the ground heat flux then transfers heat downward. Because air temperature is lower than land surface temperature, heat is transferred upward from soil to the land surface; the low thermal conductivity of the organic soil can prevent the soil from cooling. On the other hand, snowfall in winter may form a snow layer that will insulate the soil and make the simulations less sensitive to thermal conductivity. This may be the reason why the OGN-simulated winter soil temperature is higher compared 


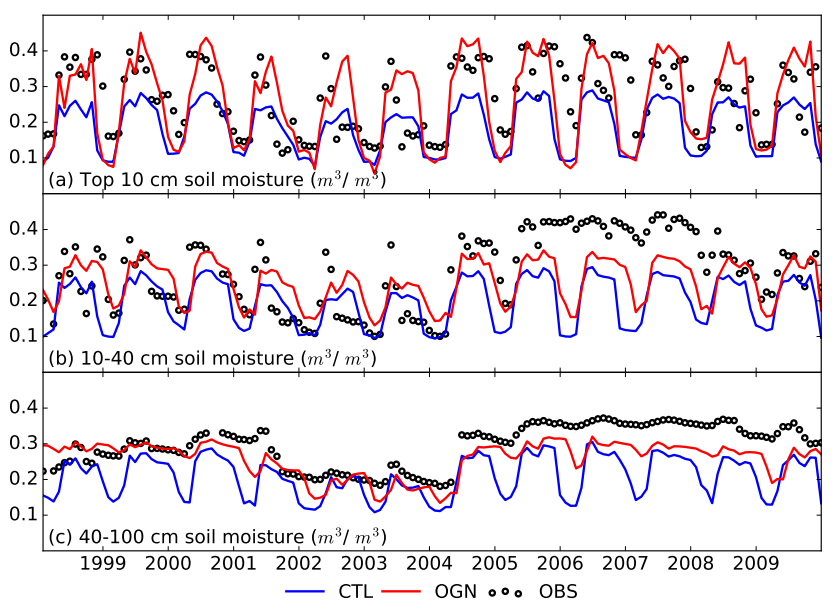

Figure 5. Observed and Noah-MP-simulated monthly soil moisture for BERMS SK-OAS site at a depth of (a) top $10 \mathrm{~cm}$, (b) $10-40 \mathrm{~cm}$, and (c) $40-100 \mathrm{~cm}$.

to CTL simulations. With the organic soil layer on the top, the reduction of surface layer saturation levels in wintertime (Fig. 5) reduces the heat loss through evaporation. The winter soil temperature then becomes significantly higher compared with the CTL experiment. On the contrary, the higher soil water content in the topsoil layer during summertime (Fig. 5) increases the heat loss through evaporation; the summer soil temperature then becomes significantly lower compared with the CTL experiment.

\subsection{Seasonal cycles of sensible and latent heat flux}

Simulated differences in top-layer soil temperature and liquid soil water content lead to the differences in simulated surface energy fluxes. Figure 6 shows that the CTL run captures the observed monthly mean daytime sensible heat and latent heat flux reasonably well. However, SH is underestimated in spring and overestimated in summer. Accordingly, LH is overestimated in spring and underestimated in summer during most of the time period except for drought years 2002-2003 where LH is slightly overestimated. Generally, the OGN simulations show similar characteristics to the CTL, with improved correlation coefficients between observations and simulations: increasing from 0.88 (CTL) to 0.92 (OGN) for $\mathrm{SH}$ and from 0.94 (CTL) to 0.96 (OGN) for $\mathrm{LH}$ (Fig. 7). Overall, both CTL and OGN perform well in winter when snow is present and fluxes are small. During the spring snowmelt season, the OGN results are much better than the CTL (Figs. 6 and 7).

The OGN simulations also improved the underestimation of SH in spring in CTL, but they still overestimate summer $\mathrm{SH}$. The reason for high bias in summer SH will be further discussed in Sect. 4.4. SH and especially LH show improvement in OGN compared to CTL, which is related to timing of soil thaw and warming in spring. CTL thaws the soil too
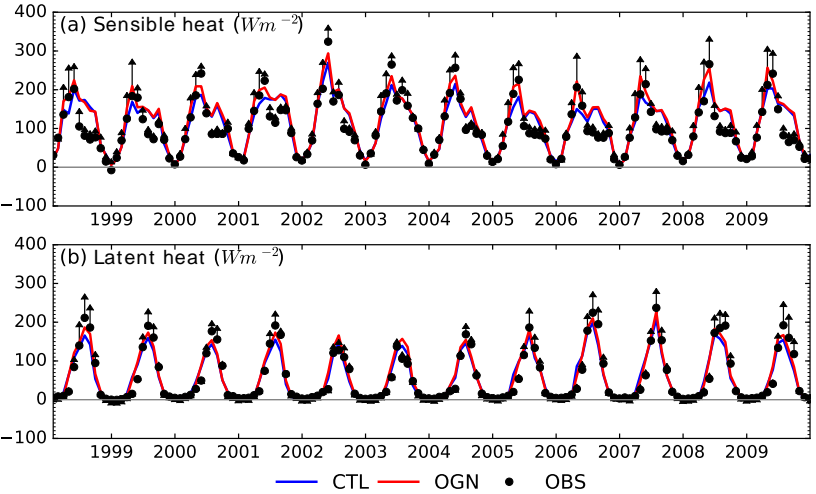

Figure 6. Observed and the Noah-MP-simulated (CTL and OGN) daytime monthly average sensible and latent heat flux above the canopy. Error bars represent the average and deviations $[(\mathrm{RN}-G) \times B /(1+B)$ for $\mathrm{SH}$, and $(\mathrm{RN}-G) /(1+B)$ for $\mathrm{LH}]$ from observations, and $\mathrm{B}$ is the Bowen ratio $(B=\mathrm{SH} / \mathrm{LH})$.

early, causing a premature rise in LH in spring (April-May) and an associated underestimation of spring $\mathrm{SH}$. The spring (April-May) fluxes are much improved in the OGN parameterization. However, both OGN and CTL retain a serious positive bias in SH from June to September, especially for wet years. The reduction of surface layer saturation levels in OGN led to lower soil evaporation and associated reductions in the total latent heat flux, and the reduction of LH is accompanied by a rise in SH (Fig. 6).

\subsection{Impact of organic soil on diurnal cycle of surface energy and hydrology}

The quality of nighttime flux-tower data is questionable (Chen et al., 2015), especially for OAS located in a boreal forest. Therefore, we focused our analysis on daytime observation data. In general, the OGN parameterization improved the simulation of daily daytime LH in terms of both RMSE and IOA, and increased IOA for SH (Table 3). Nevertheless, compared with CTL, OGN increased the bias in SH slightly by $\sim 3 \%$ (Table 3 ).

For the 12-year simulation period, the study site experienced a prolonged drought that began in July 2001 and extended throughout 2002 and 2003. We choose year 2002 and 2003 to represent typical drought years, and year 2005 and 2006 to represent typical wet years (Fig. 2), to examine the effect of the organic soil under different climate conditions. For drought years 2002-2003, OGN increased daytime SH especially in spring, and slightly decreased $\mathrm{SH}$ at nighttime (Fig. 8a, b, c, and d). LH is well simulated in both OGN and CTL (Fig. 8e, f, g, and h), with slightly increased daytime LH in OGN. OGN overestimates daytime SH compared with observations, while CTL underestimates daytime SH for spring (Fig. 8a). Both OGN and CTL overestimate SH for summer, autumn, and winter (Fig. 8b, c, d). 
Table 3. Averaged statistical indices for CTL- and OGN-simulated SH and LH compared with the observations for each year (daytime, 08:00-16:00 local time (LT)) ( $R^{2}$ : correlation coefficient square; RMSE: root mean square error; IOA: index of agreement).

\begin{tabular}{|c|c|c|c|c|c|c|c|c|c|c|c|c|}
\hline \multirow[t]{3}{*}{ Year } & \multicolumn{6}{|c|}{$\mathrm{SH}$} & \multicolumn{6}{|c|}{$\mathrm{LH}$} \\
\hline & \multicolumn{3}{|c|}{ CTL } & \multicolumn{3}{|c|}{ OGN } & \multicolumn{3}{|c|}{ CTL } & \multicolumn{3}{|c|}{ OGN } \\
\hline & $R^{2}$ & RMSE & IOA & $R^{2}$ & RMSE & IOA & $R^{2}$ & RMSE & IOA & $R^{2}$ & RMSE & IOA \\
\hline 1998 & 0.56 & 80.92 & 0.83 & 0.65 & 81.40 & 0.85 & 0.72 & 51.00 & 0.91 & 0.76 & 47.70 & 0.93 \\
\hline 1999 & 0.64 & 64.30 & 0.88 & 0.69 & 68.59 & 0.88 & 0.74 & 44.52 & 0.92 & 0.76 & 43.01 & 0.93 \\
\hline 2000 & 0.62 & 71.20 & 0.87 & 0.68 & 74.27 & 0.88 & 0.70 & 47.46 & 0.90 & 0.71 & 46.19 & 0.91 \\
\hline 2001 & 0.72 & 63.09 & 0.90 & 0.78 & 66.84 & 0.91 & 0.78 & 40.36 & 0.93 & 0.81 & 36.85 & 0.95 \\
\hline 2002 & 0.75 & 69.60 & 0.91 & 0.77 & 71.41 & 0.92 & 0.69 & 37.24 & 0.91 & 0.70 & 39.66 & 0.91 \\
\hline 2003 & 0.77 & 56.52 & 0.93 & 0.79 & 56.74 & 0.94 & 0.72 & 36.45 & 0.91 & 0.73 & 42.02 & 0.90 \\
\hline 2004 & 0.72 & 61.88 & 0.91 & 0.75 & 64.82 & 0.92 & 0.73 & 39.84 & 0.92 & 0.74 & 40.15 & 0.92 \\
\hline 2005 & 0.69 & 60.98 & 0.90 & 0.76 & 60.59 & 0.92 & 0.73 & 43.29 & 0.92 & 0.78 & 39.75 & 0.94 \\
\hline 2006 & 0.60 & 67.70 & 0.86 & 0.68 & 70.16 & 0.88 & 0.77 & 49.58 & 0.93 & 0.80 & 45.36 & 0.94 \\
\hline 2007 & 0.65 & 65.15 & 0.89 & 0.72 & 65.28 & 0.90 & 0.76 & 46.79 & 0.93 & 0.81 & 42.49 & 0.95 \\
\hline 2008 & 0.71 & 63.54 & 0.91 & 0.76 & 68.15 & 0.91 & 0.76 & 44.95 & 0.93 & 0.80 & 40.79 & 0.95 \\
\hline 2009 & 0.69 & 66.52 & 0.90 & 0.72 & 69.38 & 0.90 & 0.72 & 43.77 & 0.91 & 0.74 & 43.32 & 0.92 \\
\hline
\end{tabular}
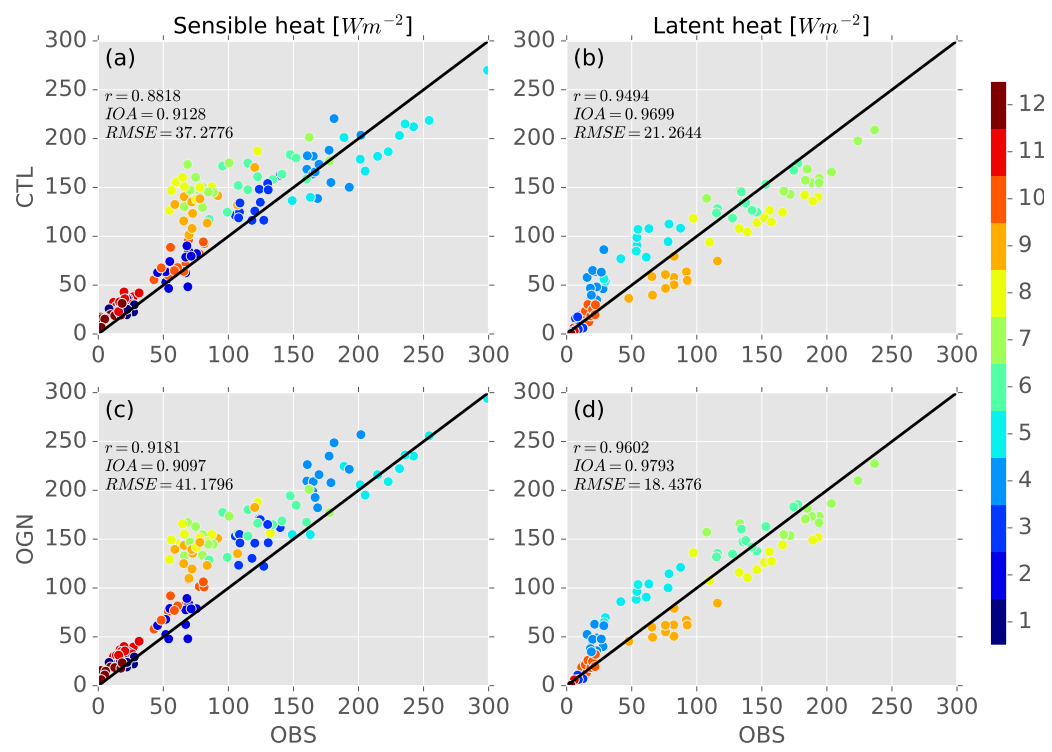

Figure 7. Scatter plots of the daytime monthly averaged (a) sensible heat fluxes and (b) latent heat fluxes (W m ${ }^{-2}$ ) for CTL vs. the observation above the canopy; the monthly averaged (c) sensible heat fluxes and (d) latent heat fluxes $\left(\mathrm{W} \mathrm{m}^{-2}\right)$ for OGN vs. the observation above the canopy. The color represents each month from January (1) to December (12).

For wet years (Fig. 9), OGN produces higher daytime SH than CTL in general. For spring, OGN-simulated SH agrees with the observation better than CTL, but it is similar to or slightly worse than CTL for other seasons. Simulated LH for both OGN and CTL agree with observations well, with an improvement by OGN in spring, because the snowmelt process dominates during spring months. For other seasons, the OGN results are close to CTL.

It is clear from Figs. 4, 8, and 9 that in both CTL and OGN, summer sensible heat fluxes are overestimated for wet and dry years. We hypothesized that such high bias in summer sensible heat flux is partly attributed to energy imbalance in observations. We then calculated the energy balance residual term: Rnet - $(\mathrm{SH}+\mathrm{LH}+G)$ for summer months (June, July, and August). In wet years, $G$ in CTL and OGN is close to observed values; modeled latent heat flux is underestimated by $\sim 10 \mathrm{~W} \mathrm{~m}^{-2}$; modeled sensible heat flux is overestimated by $\sim 30 \mathrm{~W} \mathrm{~m}^{-2}$; and the residual term is $\sim 17 \mathrm{~W} \mathrm{~m}^{-2}$. Hence, it is reasonable to argue that the surface energy imbalance $\left(\sim 17 \mathrm{~W} \mathrm{~m}^{-2}\right)$ in observations contributes to a large portion of the $\sim 30 \mathrm{~W} \mathrm{~m}^{-2}$ high bias in sensible heat fluxes. In dry 


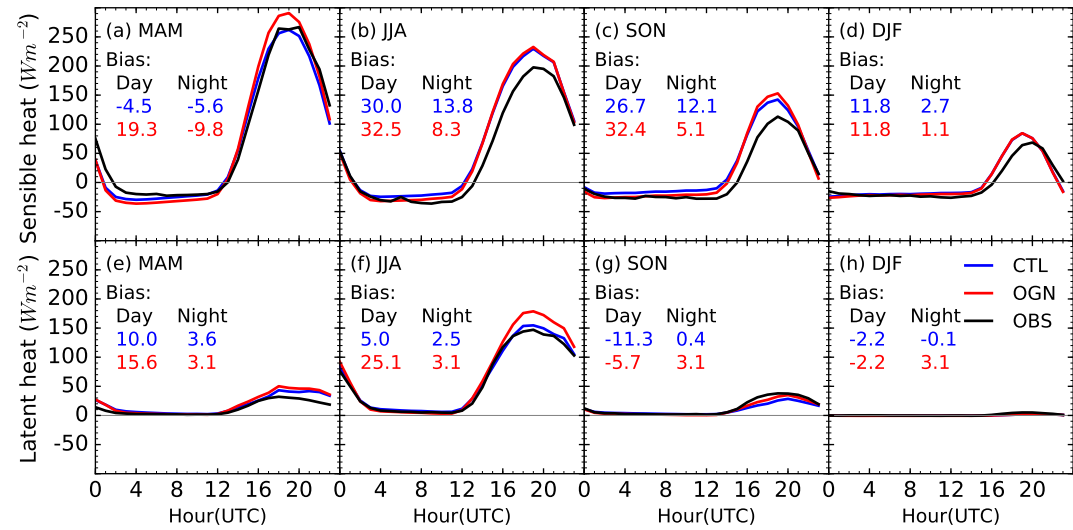

Figure 8. Comparison of the seasonal averaged diurnal cycle of the sensible and latent heat fluxes at OAS site for drought years.

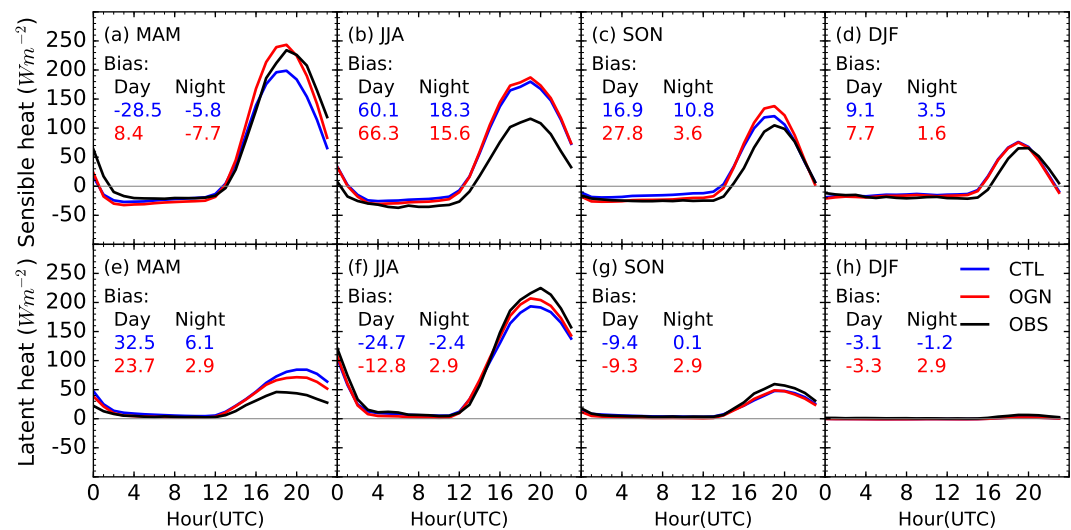

Figure 9. Comparison of the seasonal averaged diurnal cycle of the sensible and latent heat fluxes at OAS site for wet years.

years, the summer energy imbalance $\left(\sim 15 \mathrm{~W} \mathrm{~m}^{-2}\right)$ is nearly equal to the high bias in sensible heat flux $\left(\sim 15 \mathrm{~W} \mathrm{~m}^{-2}\right)$.

\subsection{Impact of an organic soil horizon on annual cycle of surface energy and hydrology}

In the previous section, it is clear that the incorporation of the top organic layer helps improve the simulation of the diurnal cycle of the surface energy and hydrologic components in spring season. In the following, we focus on a detailed analysis of the annual cycle of the surface energy and hydrology variables for dry (Fig. 10) vs. wet years (Fig. 11). Between June and September as shown in Fig. 10h, the upper two soil layers were unfrozen. The topsoil is wetter in OGN for both dry and wet years compared with CTL because organic soil can retain more water. As discussed in Sect. 4.2, for the deep soil layers, the liquid water content is influenced by the soil temperature and the movements of the soil liquid water content between soil layers. Since the soil hydraulic conductivity is higher for OGN than mineral soil, the water moves faster into deep soil layers than CTL; therefore the OGN simulates higher soil liquid water content in deep layers. OGN has a major impact on the daily cycle of soil temperature. Consis- tent with discussions in Sect. 4.2, the soil temperature below $10 \mathrm{~cm}$ simulated by OGN is lower in summer and higher in winter than that of the CTL simulation, and the OGN simulation shows less bias than the CTL simulation (Fig. 4). In the OGN simulation, the water moves faster into deep layers than in the CTL simulation, leading to more infiltrated water in the deep soil and hence a higher base flow. Consequently, the total runoff is increased. Due to the high soil porosity of the organic soil, OGN simulation shows higher soil-ice fraction at the topsoil layer during the freezing periods. The higher water capacity and higher soil-ice fraction of the organic soil then reduce liquid water content/soil moisture, leading to less evaporation (i.e., latent heat flux) during spring freezing periods, and a compensating increase of the sensible heat flux.

By adding an organic soil layer, the soil-ice content becomes higher due to higher porosity. For dry years, the impact of the organic soil on surface and subsurface runoff is not significant (Fig. 10e, f). The increase in the summer latent heat flux and sensible heat flux are compensated by a decrease in soil heat flux, leading to a significant decrease in summer soil temperature. In winter, the latent and sensible 


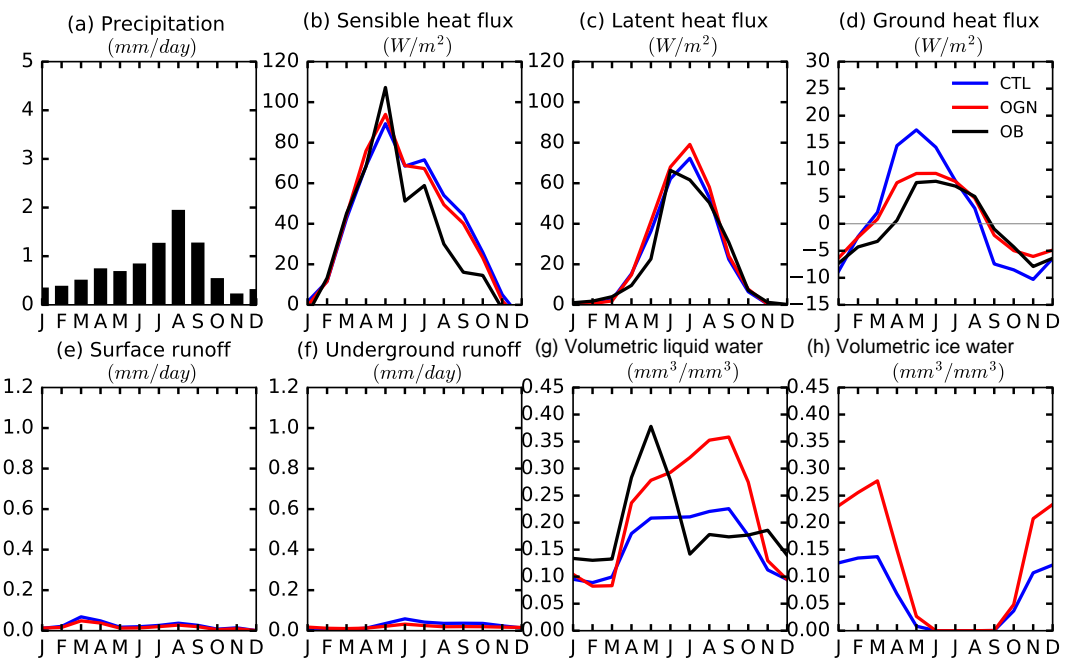

Figure 10. Annual cycle of selected surface energy and hydrologic cycle fields for drought years. The black line is the observation. Note that (a) is the observed precipitation, (b) is sensible heat flux, (c) is latent heat flux, (d) is ground heat flux, (e) is surface runoff, (f) is underground runoff, $(\mathbf{g})$ is volumetric liquid water content for soil layer one, (h) is volumetric ice water content for soil layer one.

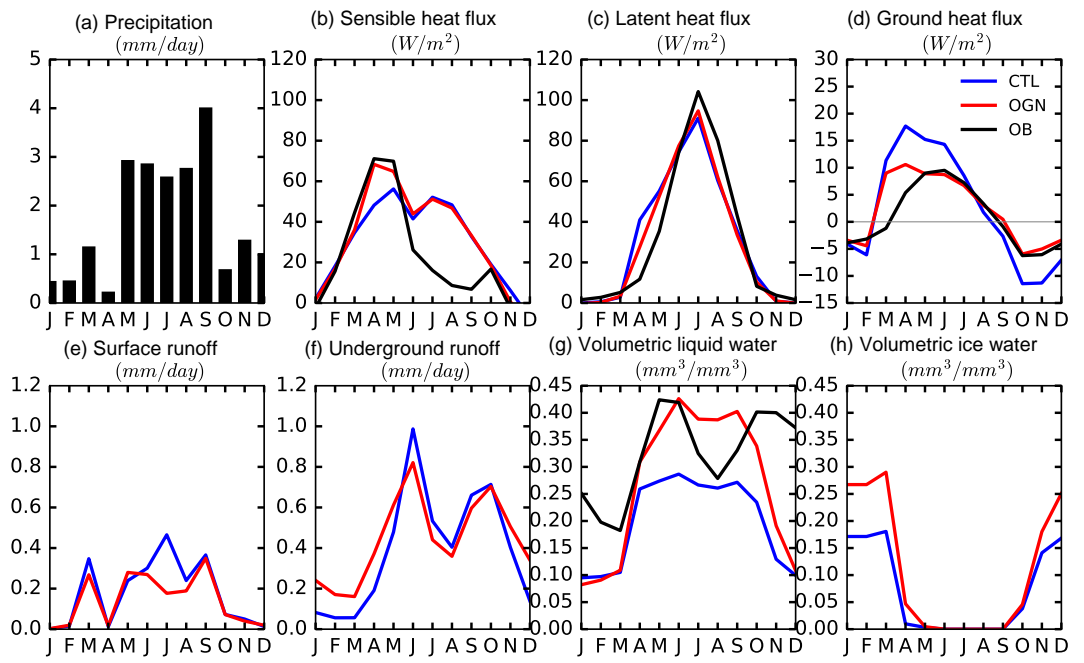

Figure 11. Annual cycle of selected surface energy and hydrologic cycle fields for wet years. The black line is the observation. Note that (a) is the observed precipitation, (b) is sensible heat flux, (c) is latent heat flux, (d) is ground heat flux, (e) is surface runoff, (f) is underground runoff, (g) is volumetric liquid water content for soil layer one, (h) is volumetric ice water content for soil layer one.

heat fluxes are not modified by the organic soil, but increased soil heat flux leads to an increased soil temperature in winter. The most prominent change by including the organic soil layer is the partition between vegetation transpiration and direct ground evaporation (Fig. 12a and b), where the OGN simulation slightly increased ground surface evaporation and vegetation transpiration.

For wet years (Fig. 11), the impact of the organic soil on surface and subsurface runoff becomes more significant, especially for subsurface runoff. The organic soil decreases the surface runoff during the summer season, and increases the subsurface runoff during the freezing periods, while it decreases the subsurface runoff during summer season. Because of the higher surface layer soil-ice content, the increase of subsurface flow should be due to the production of a wetter soil profile by OGN. The sensible heat flux also increases significantly in spring, with an associated reduction in latent heat flux and soil heat flux. The summer soil temperature also decreases but to a lesser degree than that in dry years, because the soil heat flux decreases less compared with dry years. Unlike dry years, there is a significant runoff change in wet years, and the ground evaporation is also decreased (Fig. 12c and d). OGN produces more soilice content and higher soil porosity, and leads to higher soil 


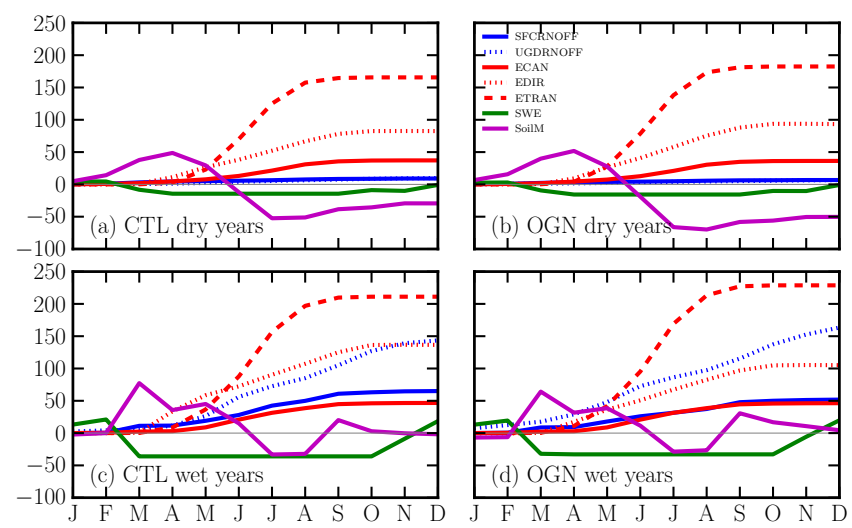

Figure 12. Water budgets: blue lines are accumulated surface runoff $(\mathrm{mm})$, blue dots are accumulated underground runoff $(\mathrm{mm})$, red lines are accumulated evaporation of intercepted water $(\mathrm{mm})$, red dots are accumulated ground surface evaporation $(\mathrm{mm})$, red dash lines are accumulated transpiration $(\mathrm{mm})$, green lines are snow water equivalent changes $(\mathrm{mm})$, purple lines are soil water content changes in the soil column $(\mathrm{mm})$; (a, b) are averaged for 20022003; (c, d) are averaged for 2005-2006.

water content than CTL simulations as the higher ice content severely restricts movement of water out of the soil column. In the wet season, by adding an organic topsoil layer, the soil water increases due to the infiltration of the soil water into the deep soil. This then leads to an increase in the subsurface runoff. As a consequence, the volumetric liquid water becomes higher in summer for OGN compared with CTL simulation.

\section{Summary and conclusions}

In this study, the Noah-MP LSM was applied at the BERMS Old Aspen site to investigate the impact of incorporating a realistic organic soil horizon on simulated surface energy and water cycle components. This site has about an $8-10 \mathrm{~cm}$ deep organic forest-floor soil horizon, typical of boreal deciduous broadleaf forests. When including, for the first time, an organic soil parameterization within the Noah-MP model, simulated sensible heat flux and latent heat flux are improved in spring, especially in wet years, which is mostly related to the timing of spring soil thaw and warming. However, in summer the model overestimated sensible heat fluxes. Such high bias in summer sensible heat flux is largely attributed to surfaceenergy imbalance in observations, especially in dry years. Due to lower thermal conductivity, the OGN-simulated soil temperature was decreased during summer and slightly increased during winter compared with the CTL simulation, and the OGN-simulated soil temperature $(10-100 \mathrm{~cm})$ was more consistent with observations and with previous studies (Lawrence and Slater, 2008). Simulated top-layer soil moisture is better in OGN than in CTL in summer but worse in winter.
Additionally, due to higher porosity of the organic soil, the OGN simulation was able to retain more soil water content in summer. However, the effects of including an organic soil layer on soil temperature are not uniform throughout the soil depth and year, and those effects are more prominent in summer and in deep soils.

For drought years, the OGN simulation substantially modified the partition between direct soil evaporation and vegetation transpiration. When water is limited in drought years, the OGN simulation slightly increased the direct soil evaporation and produced higher summer total evapotranspiration. Increased latent heat flux and sensible heat flux in summer in OGN are compensated by decreased soil heat flux, leading to reduced soil temperature in summer. For wet years, the OGN-simulated latent heat fluxes are similar to CTL, except for the spring season where OGN produced less evaporation. In addition, the impact of the organic soil on subsurface runoff is substantial with much higher runoff in freezing periods and lower runoff in summer season.

This preliminary study explored the effects of incorporating organic soil parameterization in Noah-MP on the surface energy and water cycles for one flux site in a boreal forest area. Given the important role of boreal forests in the regional climate system through reducing winter albedo and also acting as a carbon sink and water source to the atmosphere, further work is needed to evaluate the Noah-MP with organic soil parameterization at regional scales. We plan to evaluate the performance of the offline Noah-MP model and Noah-MP coupled with WRF for a broad boreal forest region including Alberta and Saskatchewan.

\section{Data availability}

The code for incorporation of an organic soil layer in the Noah-MP land surface model is available upon request from Liang Chen at the University of Saskatchewan (liang.chen@usask.ca). The FLUXNET data are publicly available from the ORNL DAAC (Distributed Active Archive Center) at ftp://daac.ornl.gov/data/fluxnet/fluxnet_canada/ data/SK-OldAspen/ (ORNL DAAC, 2016).

Acknowledgements. The author Liang Chen acknowledges support from the National Basic Research Program (grant no. 2012CB956203) and the National Natural Science Foundation of China (grant no. 41305062). The authors Liang Chen, Yanping $\mathrm{Li}$, and Alan Barr gratefully acknowledge the support from Global Institute of Water Security at University of Saskatchewan. Fei Chen, Michael Barlage, and Bingcheng Wan appreciate the support from the Water System Program at the National Center for Atmospheric Research (NCAR), and NOAA MAPP-CTB grant (NA14OAR4310186). NCAR is sponsored by the National Science Foundation. Any opinions, findings, conclusions or recommendations expressed in this publication are those of the authors and do not necessarily reflect the views of the National Science Foundation 
Edited by: L. Zhang

Reviewed by: two anonymous referees

\section{References}

Amiro, B. D., Barr, A. G., Black, T. A., Iwashita, H., Kljun, N., McCaughey, J. H., Morgenstern, K., Murayama, S., Nesic, Z., Orchansky, A. L., and Saigusa, N.: Carbon, energy and water fluxes at mature and disturbed forest sites, Saskatchewan, Canada, Agr. Forest Meteorol., 136, 237-251, 2006.

Ball, J. T., Woodrow, I. E., and Berry, J. A.: A model predicting stomatal conductance and its contribution to the control of photosynthesis under different environmental conditions, in: Process in Photosynthesis Research, Vol. 1, edited by: Biggins, J., 221234, Martinus Nijhoff, Dordrecht, Netherlands, 1987.

Barlage, M., Tewari, M., Chen, F., Miguez-Macho, G., Yang, Z. L., and Niu, G. Y.: The effect of groundwater interaction in North American regional climate simulations with WRF/NoahMP, Climatic Change, 129, 485-498, 2015.

Barr, A. G., Black, T. A., Hogg, E. H., Kljun, N., Morgenstern, K., and Nesic, Z.: Inter-annual variability in the leaf area index of a boreal aspen-hazelnut forest in relation to net ecosystem production, Agr. Forest Meteorol., 126, 237-255, 2004.

Barr, A. G., Morgenstern, K., Black, T. A., McCaughey, J. H., and Nesic, Z.: Surface energy balance closure by the eddy-covariance method above three boreal forest stands and implications for the measurement of the $\mathrm{CO}_{2}$ flux, Agr. Forest Meteorol., 140, 322337, 2006

Bartlett, P. A., McCaughey, J. H., Lafleur, P. M., and Verseghy, D. L.: A comparison of the mosaic and aggregated canopy frameworks for representing surface heterogeneity in the Canadian boreal forest using CLASS: A soil perspective, J. Hydrol., 266, 1539, 2002.

Beringer, J., Tapper, N. J., McHugh, I., Chapin, F., Lynch, A. H., Serreze, M. C., and Slater, A.: Impact of arctic treeline on synoptic climate, Geophys. Res. Lett., 28, 4247-4250, 2001.

Boelter, D. H.: Important physical properties of peat materials. Proceedings of the 3rd International Peat Congress, Quebec, 150 156,1968

Bonan, G. B.: Atmosphere-biosphere exchange of carbon dioxide in boreal forests, J. Geophys. Res., 96, 7301-7312, doi:10.1029/90JD02713, 1991.

Bonan, G. B.: Effects of land use on the climate of the United States, Climatic Change, 37, 449-486, 1997.

Bonan, G. B., Pollard, D., and Thompson, S. L.: Effects of Boreal Forest Vegetation on Global Climate, Nature, 359:, 716-718, 1992.

Brutsaert, W. A.: Evaporation Into the Atmosphere, 299 pp., D. Reidel, Dordrecht, the Netherlands, 1982.

Bryant, D., Nielsen, D., Tangley, L., Sizer, N., Miranda, M., Brown, P., Johnson, N., Malk, A., and Miller, K.: The last frontier forests: ecosystems and economies on the edge. What is the status of the worlds remaining large natural forest ecosystems?, Washington, D.C., World Resources Institute [WRI], Forest Frontiers Initiative, 39 pp., 1997.

Cai, X., Yang, Z. L., David, C. H., Niu, G. Y., and Rodell, M.: Hydrological evaluation of the Noah-MP land surface model for the
Mississippi River Basin, J. Geophys. Res.-Atmos., 119, 23-38, 2014.

Chen, F. and Dudhia, J.: Coupling an advanced land surfacehydrology model with the Penn State-NCAR MM5 modeling system. Part I: Model implementation and sensitivity, Mon. Weather Rev., 129, 569-585, 2001.

Chen, F. and Mitchell, K.: Using GEWEX/ISLSCP forcing data to simulate global soil moisture fields and hydrological cycle for 1987-1988, J. Meteorol. Soc. Jpn., 77, 1-16, 1999.

Chen, F., Mitchell, K., Schaake, J., Xue, Y., Pan, H. L., Koren, V., Duan, Q. Y., Ek, M., and Betts, A.: Modeling of land surface evaporation by four schemes and comparison with fife observations, J. Geophys. Res.-Atmos., 101, 7251-7268, 1996.

Chen, F., Barlage, M. J., Tewari, M., Rasmussen, R. M., Jin, J., Lettenmaier, D., Livneh, B., Lin, C., Miguez-Macho, G., Niu, G. Y., Wen, L., and Yang, Z. L.: Modeling seasonal snowpack evolution in the complex terrain and forested Colorado Headwaters region: A model intercomparison study, J. Geophys. Res.-Atmos., 119, 13795-13819, doi:10.1002/2014JD022167, 2014.

Chen, F., Zhang, G., Barlage, M., Zhang, Y., Hicke, J. A., Meddens, A., Zhou, G., Massman, W. J., and Frank, J.: An Observational and Modeling Study of Impacts of Bark Beetle-Caused Tree Mortality on Surface Energy and Hydrological Cycles, J. Hydrometeorol., 16, 744-761, doi:10.1175/JHM-D-14-0059.1, 2015.

Chotamonsak, C., Salathe Jr., E. P., Kreasuwan, J., and Chantara, S.: Evaluation of precipitation simulations over Thailand using a WRF regional climate model, Chiang Mai Jounal of Science, 39, 623-638, 2012.

Ciais, P., Tans, P. P., Trolier, M., White, J. W. C., and Francey, R. J.: A large northern hemisphere terrestrial $\mathrm{CO}_{2}$ sink indicated by the ${ }^{13} \mathrm{C} /{ }^{12} \mathrm{C}$ ratio of atmospheric $\mathrm{CO}_{2}$, Science-New York then Washington, 1098-1098, 1995.

Clapp, R. B. and Hornberger, G. M.: Empirical equations for some soil hydraulic properties, Water Resour. Res., 14, 601-604, 1978.

Clark, M. P., Nijssen, B., Lundquist, J. D., Kavetski, D., Rupp, D. E., Woods, R. A., Freer, J. E., Gutmann, E. D., Wood, A. W., Brekke, L. D., and Arnold, J. R.: A unified approach for processbased hydrologic modeling: 1. Modeling concept, Water Resour. Res., 51, 2498-2514, doi:10.1002/2015WR017198, 2015.

Cosgrove, B. A., Lohmann, D., Mitchell, K. E., Houser, P. R., Wood, E. F., Schaake, J. C., Robock, A., Marshall, C., Sheffield, J., Duan, Q., Luo, L., Higgins, R. W., Pinker, R. T., Tarpley, J. D., and Meng, J.: Real-time and retrospective forcing in the North American Land Data Assimilation System (NLDAS) project, J. Geophys. Res., 108, 8842, doi:10.1029/2002JD003118, 2003.

Dai, Y., Zeng, X., Dickinson, R. E., Baker, I., Bonan, G. B., Bosilovich, M. G., Denning, A. S., Dirmeyer, P. A., Houser, P. R., Niu, G., Oleson, K. W., Schlosser, C. A., and Yang, Z. L.: The Common Land Model, B. Am. Meteorol. Soc., 84, 10131023, doi:10.1175/BAMS-84-8-1013, 2003.

Dickinson, R. E., Henderson-Sellers, A., Kennedy, P. J., and Wilson, M. F.: Biosphere-atmosphere Transfer Scheme (BATS) for the NCAR Community Climate Model, NCAR Technical Note NCAR/TN-275-+STR, doi:10.5065/D6668B58, 1986.

Dingman, S. L.: Physical Hydrology, MacMillan Publishing Company, New York, 1994.

Ek, M. B., Mitchell, K. E., Lin, Y., Rogers, E., Grunmann, P., Koren, V., Gayno, G., and Tarpley, J. D.: Implementation of Noah 
land surface model advances in the National Centers for Environmental Prediction operational mesoscale Eta model, J. Geophys. Res., 108, 8851, doi:10.1029/2002JD003296, 2003.

Farouki, O. T.: Thermal properties of soils, Report No. CRRELMONO-81-1, COLD REGIONS RESEARCH AND ENGINEERING LAB HANOVER NH, Vol. 81, CRREL Monograph, 1981.

Gao, Y., Li, K., Chen, F., Jiang, Y., and Lu, C.: Assessing and improving Noah-MP land model simulations for the central Tibetan Plateau, J. Geophys. Res.-Atmos., 120, 9258-9278, doi:10.1002/2015JD023404, 2015.

Jordan, R.: A one-dimensional temperature model for a snow cover, Spec. Rep. 91-16, Cold Reg. Res. and Eng. Lab., US Army Corps of Eng., Hanover, NH, 1991.

Koven, C., Friedlingstein, P., Ciais, P., Khvorostyanov, D., Krinner, G., and Tarnocai,C.: On the formation of high-latitude soil carbon stocks: Effects of cryoturbation and insulation by organic matter in a land surface model, Geophys. Res. Lett., 36, L21501, doi:10.1029/2009GL040150, 2009.

Lawrence, D. M. and Slater, A. G.: Incorporating organic soil into a global climate model, Clim. Dynam., 30, 145-160, 2008.

Letts, M. G., Roulet, N. T., Comer, N. T., Skarupa, M. R., and Verseghy, D. L.: Parametrization of peatland hydraulic properties for the Canadian land surface scheme, Atmos. Ocean, 38, 141-160, 2000

Levine, E. R. and Knox, R. G.: Modeling soil temperature and snow dynamics in northern forests, J. Geophys. Res., 102, $29407-$ 29416, doi:10.1029/97JD01328, 1997.

Mölders, N. and Romanovsky, V. E.: Long-term evaluation of the Hydro-Thermodynamic Soil-Vegetation Scheme's frozen ground/permafrost component using observations at Barrow, Alaska, J. Geophys. Res., 111, D04105, doi:10.1029/2005JD005957, 2006.

Nicolsky, D. J., Romanovsky, V. E., Alexeev, V. A., and Lawrence, D. M.: Improved modeling of permafrost dynamics in a GCM land-surface scheme, Geophys. Res. Lett., 34, L08501, doi:10.1029/2007GL029525, 2007.

Niu, G.-Y. and Yang, Z.-L.: Effects of frozen soil on snowmelt runoff and soil water storage at a continental scale, J. Hydrometeorol., 7, 937-952, doi:10.1175/JHM538.1, 2006.

Niu, G.-Y., Yang, Z.-L., Dickinson, R. E., and Gulden, L. E.: A simple TOPMODEL-based runoff parameterization (SIMTOP) for use in global climate models, J. Geophys. Res., 110, D21106, doi:10.1029/2005JD006111, 2005.

Niu, G.-Y., Yang, Z.-L., Dickinson, R. E., Gulden, L. E., and $\mathrm{Su}, \mathrm{H}$.: Development of a simple groundwater model for use in climate models and evaluation with Gravity Recovery and Climate Experiment data, J. Geophys. Res., 112, D07103, doi:10.1029/2006JD007522, 2007.

Niu, G. Y., Yang, Z. L., Mitchell, K. E., Chen, F., Ek, M. B., Barlage, M., Kumar, A., Manning, K., Niyogi, D., and Rosero, E.: The community Noah land surface model with multiparameterization options (Noah-MP): 1. Model description and evaluation with local-scale measurements, J. Geophys. Res., 116, D12109, doi:10.1029/2010JD015139, 2011.
Oleson, K. W., Niu, G. Y., Yang, Z. L., Lawrence, D. M., Thornton, P. E., Lawrence, P. J., Stöckli, R., Dickinson, R. E., Bonan, G. B., Levis, S., Dai, A., and Qian, T.: Improvements to the Community Land Model and their impact on the hydrological cycle, J. Geophys. Res., 113, G01021, doi:10.1029/2007JG000563, 2008.

ORNL DAAC: FLUXNET data, available at: ftp://daac.ornl.gov/ data/fluxnet/fluxnet_canada/data/SK-OldAspen/, last access: 2 July 2016.

Pilotto, I. L., Rodríguez, D. A., Tomasella, J., Sampaio, G., and Chou, S. C.: Comparisons of the Noah-MP land surface model simulations with measurements of forest and crop sites in Amazonia, Meteorol. Atmos. Phys., 127, 711-723, doi:10.1007/s00703-015-0399-8, 2015.

Radforth, N. W. and Brawner, C. O.: Muskeg and the northern environment in Canada. In Muskeg Research Conference 1973: Edmonton, Alberta, University of Toronto Press, 1977.

Rinke, A., Kuhry, P., and Dethloff, K.: Importance of a soil organic layer for Arctic climate: A sensitivity study with an Arctic RCM, Geophys. Res. Lett., 35, L13709, doi:10.1029/2008GL034052, 2008.

Sellers, P. J., Randall, D. A., Collatz, G. J., Berry, J. A., Field, C. B., Dazlich, D. A., Zhang, C., Collelo, G. D., and Bounoua, L.: A revised land surface parameterization $(\mathrm{SiB} 2)$ for atmospheric GCMs. Part I: Model formulation, J. Climate, 9, 676-705, 1996.

Thomas, G. and Rowntree, P. R.: The Boreal Forests and Climate, Q. J. Roy. Meteor. Soc., 118, 469-497, doi:10.1002/qj.49711850505, 1992.

Verseghy, D. L.: CLASS-A Canadian land surface scheme for GCMS: I. Soil model, Int. J. Climatol., 11, 111-133, doi:10.1002/joc.3370110202, 1991.

Viterbo, P. and Betts, A. K.: Impact on ECMWF forecasts of changes to the albedo of the boreal forests in the presence of snow, J. Geophys. Res., 104, 27803-27810, doi:10.1029/1998JD200076, 1999.

Yang, Z. L., Dickinson, R. E., Henderson-Sellers, A., and Pitman, A. J.: Preliminary study of spin-up processes in land surface models with the first stage data of project for intercomparison of land surface parameterization schemes phase 1 (a), J. Geophys. Res.-Atmos., 100, 16553-16578, 1995.

Yang, Z.-L., Niu, G.-Y., Mitchell, K. E., Chen, F., Ek, M. B., Barlage, M., Longuevergne, L., Manning, K., Niyogi, D., Tewari, M., and Xia, Y.: The community Noah land surface model with multiparameterization options (Noah-MP): 2. Evaluation over global river basins, J. Geophys. Res., 116, D12110, doi:10.1029/2010JD015140, 2011.

Zhang, G., Zhou, G., Chen, F., Barlage, M., and Xue, L.: A trial to improve surface heat exchange simulation through sensitivity experiments over a desert steppe site, J. Hydrometeorol., 15, 664-684, doi:10.1175/jhm-d-13-0113.1, 2014.

Zheng, D., van der Velde, R., Su, Z., Wen, J., Booij, M. J., Hoekstra, A. Y., and Wang, X.: Under-canopy turbulence and root water uptake of a Tibetan meadow ecosystem modeled by Noah-MP, Water Resour. Res., 51, 5735-5755, doi:10.1002/2015WR017115, 2015. 